\title{
Indications and visual outcome following optical keratoplasty and their correlation with graft failure
}

\author{
Nasrin Y, Rashmi Rath \\ Sankar Foundation Eye Institute, Naiduthota, Visakhapatnam, Andhra Pradesh, India, Visakhapatnam, India
}

\begin{abstract}
BACKGROUND: The aim was to study the indications for optical keratoplasty and its correlation with risk factors, postoperative course, and graft survival outcome.

MATERIAL AND METHODS: A non-randomized prospective interventional descriptive study was carried out on 71 eyes of 71 patients aged between 15 to 75 years undergoing optical keratoplasty. Surgical procedures such as penetrating keratoplasty $(\mathrm{PK}), \mathrm{PK}+$ posterior-chamber intraocular lens implantation (PCIOL), $\mathrm{PK}+$ the absence of the lense of the eye (Aphakia), and PK + anterior vitrectomy were performed in 34, 28, 6, and 2 cases, respectively. Indications and outcomes were measured by graft survival and visual acuity. The survival rate of grafts and their correlation with variables such as corneal vascularization, previously failed grafts, history of infection, post-perforation corneal scars, graft size, type of surgery, and follow-up were assessed.

RESULTS: The most common indication was the corneal scar, measured high in agriculture laborers. There was a significant correlation observed between prognosis and graft survival $(\mathrm{p}<0.001)$. The success rate for corneal scars was around $75 \%$. At 6-months follow-up the complication observed was failed graft $(\mathrm{n}=7)$. This is due to preoperative indication in these cases were corneal scar $(\mathrm{n}=3)$, post-therapeutic $\mathrm{PK}(\mathrm{n}=2)$, adherent leucomas $(\mathrm{n}=1)$, and keratoconus $(n=1)$. The common cause of graft failure was fungal graft infection $(n=4)$. Out of 6 eyes that had graft infection, 4 underwent repeat graft (PK + PCIOL). Twenty-eight eyes underwent PK + PCIOL implantation surgery resulting in good visual acuity $(\mathrm{p}<0.001) .66 \%$ of patients achieved a best corrected visual acuity (BCVA) of $6 / 36$ or better. Patients who underwent PK + PCIOL procedure achieved a good visual outcome. The trephination of the diseased cornea of $7.5 \mathrm{~mm} / 8 \mathrm{~mm}$ graft of size allowed to achieve a good visual outcome.

CONCLUSION: The success rate in corneal scars was around $75 \%$. Graft failure seen at 6 -months post-operative follow-up was mostly associated with graft infection and repeat graft (PK + PCIOL). PK + PCIOL procedure and $7.5 \mathrm{~mm} / 8 \mathrm{~mm}$ graft of size achieved a good visual outcome. Recognition and management of complications and graft rejection early are crucial for long-term graft survival and satisfactory visual outcome.
\end{abstract}

KEY WORDS: optical keratoplasty; penetrating keratoplasty; graft rejection; corneal scar

Ophthalmol J 2021; Vol. 6, 184-192 


\section{INTRODUCTION}

Corneal blindness is a visual impairment from the cloud or scarred cornea. Corneal blindness can also be caused by an infection, ultimately affecting the cornea's transparency and leading to the blind. Globally, 284 million people are visually impaired [1, 2]. Of these, 39 million are blind, and 245 million have a moderate or severe visual impairment. $80 \%$ of blindness is avoidable. $90 \%$ of the population with visual impairments live in developing countries. This incidence is the common cause of avoidable blindness after refractive errors, cataracts, glaucoma, and diabetic retinopathy. The leading causes of visual impairment are cataract $(47.9 \%)$, followed by glaucoma $(12.3 \%)$, age-related macular degenerations (AMD) (8.7\%), corneal opacities $(5.1 \%)$, diabetic retinopathy $(4.8 \%)$, childhood blindness (3.9\%), trachoma (3.6\%), and onchocerciasis $(0.8 \%)$. In India, $0.9 \%$ of the blind are caused by corneal diseases [3]. Penetrating keratoplasty $(\mathrm{PK})$ is the surgical management of corneal blindness.

Keratoplasty is a procedure in which a patient's diseased cornea is replaced with a donor cornea. This procedure is performed in different ways, depending upon the corneal pathology. In optical keratoplasty, the aim is visual restoration. In therapeutic keratoplasty, the objective is to remove the burden of infective tissue to facilitate faster recovery and prevent the complications of perforation in a corneal ulcer.

The current study was designed to identify various optical indications for PK and evaluate the outcomes of PK regarding the visual outcome, graft survival, intraoperative and postoperative complications.

\section{MATERIAL AND METHODS}

A non-randomized, prospective, interventional, descriptive study was conducted at Sankar Foundation Eye Hospital, Visakhapatnam, Andhra Pradesh. We included 71 eyes of 71 patients who underwent PK for different corneal problems. The study duration was a year, between March 2012 and March 2013.

Inclusion criteria were as follows: patients who attended the cornea clinic of this hospital and underwent PK, age between 15-75 years, patients with corneal opacities involving the visual axis, and best-corrected visual acuity (BCVA) $<6 / 36$, with keratoconus scar, patients willing for strict compliance with the prescripted drugs for a longer period and those who came for regular follow-up, and patients who completed a minimum follow-up period of 3 months postoperatively.

Exclusion criteria were as follows: extremes of age, poor general condition, patients not willing for surgery, unable to attend follow-up of minimum 3 months, with retinal pathologies causing very poor visual prognosis, with intractable glaucoma not controlled with medical or surgical treatment, with highly vascularized corneas, and peripheral small corneal opacity.

All patients were preoperatively thoroughly examined for their eye condition and general condition. The eye examination included: visual acuity, detailed slit-lamp examination, lids and adnexal examination, B-scan wherever necessary, intraocular pressure (IOP) assessment with Goldman's applanation/noncontact tonometry wherever possible. Other ophthalmological examinations included evaluation squint, motility disorders, orbital disorders, and further ophthalmological examination. Informed consent was obtained after explaining the eye condition, surgical procedure, complications, and visual prognosis to the patient or patient's parents/guardian (if pediatric). The study was performed after approval from the institutional ethical committee. The donor corneal button was evaluated for its quality. Poor quality (low endothelial count) grafts were not considered for optical PK. All the surgeries were conducted by two experienced surgeons and consultants in the Cornea Department, Sankar Foundation Eye Hospital, Visakhapatnam.

\section{Surgical technique for penetrating keratoplasty}

The procedure was performed under peribulbar anesthesia. After draping the eye, $7-8 \mathrm{~mm}$ trephination of the corneal button has been made. Trephination was done using disposable trephines. During trephination, the corneal scar is a central point that has been taken into consideration. If the scar was eccentric, trephination was performed eccentrically. The donor button was taken after properly evaluating its tissue regarding screening for general diseases and endothelial count. The size of the taken donor button was $0.5 \mathrm{~mm}$ greater than the size of the recipient button. Donor button was made using standard punch technique with donor cornea kept in the endothelial side up in the well of Teflon block. 7.5-8.5-mm donor button was sutured onto the recipient bed using 10-0 nylon interrupted sutures. A total of 16 sutures were given at equidis- 
tant, with bite taking at approximately $90 \%$ thickness. All sutures were buried into the recipient's bed.

Cataract extraction with posterior-chamber intraocular lens implantation (PCIOL) implantation was done in the same sitting whenever a significant cataract caused a decrease in vision. Anterior vitrectomy was also performed according to necessary in the same sitting itself. Scleral fixation PCIOL was also accomplished in particular cases of aphakia where posterior capsular support was absent. According to the situation, anterior vitrectomy, pupilloplasty, and peripheral anterior synechiolysis procedures were done in the same sitting whenever necessary.

\section{Postoperative care}

Patients were admitted to the hospital one day before surgery. Postoperatively, all patients stayed in the hospital for three days and were discharged if the eye and general condition were satisfactory. Routine postoperative instructions included proper eye care and hygiene, avoidance of coughing, sneezing, and strenuous work for at least one month. Medications included: moxifloxacin $0.3 \%$ eye drops, prednisolone $1 \%$ or dexamethasone $0.1 \%$ eye drops, timolol maleate $0.5 \%$ eye drops, carboxymethylcellulose $1 \%$ eye drops, carmellose eye ointment, aceclofenac, and paracetamol tablets. Other medications were used whenever necessary. All patients were followed-up postoperatively on days: $1^{\text {st }}, 2^{\text {nd }}, 3^{\text {rd }}, 7^{\text {th }}$, $14^{\text {th }}, 30^{\text {th }}$, and at monthly intervals till 6 months postoperative, then at 3-monthly intervals. Patients were asked to come for follow-up as and when necessary between the regular schedule if they had any problem in the operated eye.

Patients were educated about signs of rejection (RSVP):

- Redness (R) - graft rejection may be associated with eye redness.

- Sensitivity $(S)$ - rejection may cause increased sensitivity to light.

- Vision (V) - rejection cause decreased vision, particularly foggy or cloudy vision.

- Pain (P) - rejection cause discomfort, irritation, and foreign body sensation.

After 3 months of follow-up, patients were asked to come for follow-up every 3 months. If any problem was noticed in the follow-up period, they were addressed promptly by the operated surgeon. Postoperatively, suture removal was done according to the steep axis after 6 months. Finally, the correction of spectacle or contact lens (either soft or rigid gas permeable) was given to attain the BCVA.

\section{RESULTS \\ Demographics}

There were 71 eyes of 71 patients operated for different corneal pathologies. All eyes underwent PK. Two experienced surgeons performed all 71 eyes surgeries. $49.2 \%$ of the patients were 40-60 years old, 3 patients (4.2\%) were younger than 20 years, around $20 \%$ were $21-40$ years, and $26.7 \%$ of the patients were above 60 years old. The mean age of patients in the study population was 51.84, with a standard deviation of 13.74 . Among the 71 operated patients, $48(67.6 \%)$ were males, and $23(32.4 \%)$ were females (male: female ratio was close to $2: 1$ ). The majority of the patients were from the low socioeconomic community.

\section{Operated eye}

The right eye was operated on in 40 patients (57.14\%), and in the remaining $31(42.86 \%)$ patients, the left eye was operated on.

\section{Indications}

The most common indications for PK were corneal scars $(\mathrm{n}=20,28 \%)$ and adherent leucomas $(\mathrm{n}=12,17 \%)$. Most of the patients were middle-aged (between 41 to 60 years - 49.2\%). Among the old-aged (above 60 years), pseudophakic bullous keratopathy (16\%) was the most common indication for keratoplasty. Among the 3 adolescents ( $<20$ years) who underwent PK, 1 was operated on for keratoconus, and 2 underwent the procedure for congenital hereditary endothelial dystrophy. Ten eyes $(14 \%)$ received repeat grafts due to previously failed grafts. Among them, 2 were single-eyed patients, the other eye-bearing vision no perception of light (PL). Corneal degenerations and dystrophies bore $14 \%$ of all causes, $7 \%$ each. One patient was operated on for aphakic bullous keratopathy.

\section{Type of surgery performed}

Thirty-four eyes (48\%) underwent PK alone. Penetrating keratoplasty along with cataract extraction and intraocular lens (IOL) implantation was done in the same sitting. Other procedures, like anterior vitrectomy, were also performed in the same sitting. $39 \%$ of eyes $(n=28)$ underwent PK and extra-capsular cataract extraction with posterior chamber IOL implantation. In 6 eyes (9\%) having corneal pathology and cataract, IOL could not be implanted due to pre-operative complications or pre-existing conditions that excluded the patients from the procedure. They were left aphakic. Two 
eyes $(3 \%)$ required anterior vitrectomy along with PK. One eye underwent PK + scleral fixation IOL in the same sitting.

\section{Best corrected visual acuity}

\section{Preoperative BCVA}

Around half of the patients (48\%) in the preoperative group had the BCVA of perception of light PL+, PR- accurate, whereas in the postoperative group $2 / 3^{\text {rd }}(66 \%)$ of patients achieved BCVA $6 / 36$. In the preoperative group, around $1 / 5^{\text {th }}(21 \%)$ had a BCVA between "hand motion" (HM) and "counting fingers close to face" (CFCF), and $1 / 4^{\text {th }}$ (24\%) patients had BCVA of between CF $1 / 4 \mathrm{~m}$ to $\mathrm{CF} 3 \mathrm{~m}$. The remaining $5(7 \%)$ patients had the BCVA between CF $>3 \mathrm{~m}$ to $6 / 60$. No patient in the preoperative group had a BCVA better than 6/60.

Forty-nine $(69 \%)$ patients had very poor preoperative BCVA, i.e., less than CFCF. Among them, most of the patients (17 patients, 35\%) had a corneal scar, followed by adherent leucomas (10 patients) and previously failed graft (10 patients). Seven of the patients with bullous keratopathy had preoperative BCVA less than CFCF.

\section{Postoperative BCVA}

The majority of the patients' final BCVA was satisfactory. $66 \%$ of patients achieved a BCVA of $6 / 36$ or better. Among them, 6 patients (7\%) achieved a visual acuity of $6 / 12$ or better. Only 3 eyes (4\%) did not improve any vision after surgery. Five patients $(7 \%)$ had a postoperative BCVA between HM to CFCF. Visual acuity between CF $1 / 4 \mathrm{~m}$ to CF $3 \mathrm{~m}$ was present in $8(12 \%)$ patients postoperatively. Eight patients (11\%) had visual acuity between CF $3 \mathrm{~m}$ and 6/60.

Among 47 patients (66\%) who achieved a good postoperative BCVA, i.e., better than 6/36, 26 (36\%) underwent PK alone. Eighteen patients (25\%) underwent PK + PCIOL. Two patients (5\%) underwent PK + Aphakia + anterior vitrectomy. Among the patients who achieved satisfactory post-operative BCVA, i.e, better than $6 / 36$, the pre-operative indications were corneal scar $(\mathrm{n}=12)$, pseudophakic bullous keratopathy $(n=9)$, adherent leucomas $(n=6)$, corneal degeneration $(n=5)$, previously failed graft $(\mathrm{n}=4)$, corneal dystrophy $(\mathrm{n}=4)$, vascular corneal opacity $(\mathrm{n}=3)$, CHED $(\mathrm{n}=2)$, keratoconus $(\mathrm{n}=1)$.

Poor post-operative BCVA, i.e., CF $3 \mathrm{~m}$ or less than that, was seen in 16 eyes (23\%). The major preoperative indications that are causing poor visual outcomes are: adherent leucomas $(\mathrm{n}=5)$, previously failed keratoplasty, mainly therapeutic PK $(n=4)$, corneal scars $(\mathrm{n}=3)$ and pseudophakic bullous keratopathy, keratoconus, corneal degeneration, and aphakic bullous keratopathy accounting 1 case for each.

Among patients with poor visual outcome (< CF 3 m), 8 underwent PK + PCIOL. PK alone and $\mathrm{PK}+$ anterior vitrectomy were required in 4 cases each, respectively. Five eyes among the post-operative low visual outcome group had a graft infection during the follow-up period, causing the graft failure. Four eyes had posterior segment pathologies in the poor visual outcome group. They include glaucomatous optic atrophy, macular scar, macular hole, and non-glaucomatous optic atrophy in 4 eyes (Tab. 1).

\begin{tabular}{|l|c|c|c|c|}
\hline \multirow{2}{*}{ Table 1. Best corrected visual acuity visual acuity (BCVA) } \\
\cline { 2 - 4 } & \multicolumn{2}{|c|}{ BCVA } & \multirow{2}{*}{ 95\% CI } & p-value \\
\cline { 2 - 4 } & No. of eyes (\%) & No. of eyes (\%) & \\
\hline PL + PR inaccurate to accurate & $34(48 \%)$ & $3(4 \%)$ & $30.56-55.72 \%$ & $0.0001^{*}$ \\
\hline HM to CFCF & $15(21 \%)$ & $5(7 \%)$ & $2.5-25.54 \%$ & $0.0166^{*}$ \\
\hline CF $1 / 4$ m to CF $3 \mathrm{~m}$ & $17(24 \%)$ & $8(12 \%)$ & $-0.75-24.46 \%$ & 0.0637 \\
\hline CF $>3$ m to $6 / 60$ & $5(7 \%)$ & $8(11 \%)$ & $-5.96-14.17 \%$ & 0.4066 \\
\hline $6 / 36$ to $6 / 18$ & $0(0 \%)$ & $42(59 \%)$ & $46.30-69.69 \%$ & $0.0001^{*}$ \\
\hline $6 / 12$ or better & $0(0 \%)$ & $5(7 \%)$ & $0.50-15.39 \%$ & $0.0237^{*}$ \\
\hline Total & $71(100 \%)$ & $71(100 \%)$ & & \\
\hline
\end{tabular}

PL - perception of light; PR — projection of rays; HM — hand motion; CFCF — counting fingers close to face; $\chi^{2}$ test as recommended by Campbell (2007) and Richardson (2011); ${ }^{*}$ significant, confidence interval (CI) calculated according to the recommended method given by Altman et al. (2000) 


\section{Follow-up period}

Among 71 operated patients, 14 completed one-year follow-up, 32 - 6-month follow-up, and $25-3$-month follow-up.

\section{Postoperative complications}

About half of the eyes $(n=35,49 \%)$ underwent smooth postoperative recovery without complications. The remaining half of the cases $(50.70 \%)$ had immediate complications. At 3 months postoperative follow-up, 18 patients and 10 patients at 6 months follow-up period had complications. Most of them resolved, and patients attained good visual recovery.

\section{Immediate postoperative complications}

The most common immediate postoperative complication was graft edema $(n=20,28 \%)$, followed by fibrin reaction in anterior chamber $(\mathrm{n}=7(10 \%)$, epithelial detachment that did not resolved with maximum topical lubrication, and required bandage contact lens application $(\mathrm{n}=6$, $8.5 \%)$, shallow anterior chamber $(\mathrm{n}=6,8.5 \%)$, Descemet's membrane detachment $(n=4,6 \%)$, raised IOP mainly due to retained viscoelastic substance in the anterior chamber $(n=3,4 \%)$, hyphema $(n=3$, $4 \%)$, loose sutures that required resuturing $(n=2$, $3 \%)$ and choroidal detachment $(\mathrm{n}=1,1 \%)$. Persistent epithelial defect (PED) was diagnosed when the defect was present more than a week after maximum topical lubrication. It was treated with BCL. The causes of PED are graft-host disparity $(\mathrm{n}=1)$ which was sutured again, and in one case, the PED was resolved with oral acyclovir $800 \mathrm{mg}$ TID for 2 weeks along with topical lubricants. Most of the complications were determined over a period of time with medication or with another surgical intervention to correct those problems.

\section{Postoperative complications at 3 months}

The most common complications seen at the 3-month follow-up period were graft infections $(\mathrm{n}=6)$. Among them, in 5 eyes graft failed ultimately, and one eye recovered satisfactory vision. Among the graft infection cases, two eyes earlier underwent therapeutic PK for fungal corneal ulcer. They acquired a graft infection (probably caused by premature stoppage of antifungal treatment after therapeutic PK), leading to failed graft. These patients were operated on with optical PK for the second time and again got the infection, ultimately causing graft failure. The other complications seen at 3-month follow-up period were: peripheral anterior synechiae (PAS) formation $(n=2)$, glaucoma $(n=2)$, graft rejection $(\mathrm{n}=1)$, graft thinning $(\mathrm{n}=1)$, failed graft $(\mathrm{n}=1)$, vascularization of graft $(n=1)$, posterior segment pathology $(n=4)$.

Peripheral anterior synechiae formation is associated with a shallow anterior chamber in the immediate postoperative period. Among the two eyes, in one eye PAS occurred because of wound leak due to loose sutures and another eye because of raised IOP. Synechiolysis by the surgical intervention was attempted in these two eyes. Graft rejection was seen in one case at a 3-month follow-up, which was resolved successfully with medication. In four eyes, posterior segment pathology was noted at a 3-month follow-up visit. They were glaucomatous optic atrophy $(\mathrm{n}=1)$, no glaucomatous optic atrophy $(\mathrm{n}=1)$, macular scar $(\mathrm{n}=1)$, macular hole $(\mathrm{n}=1)$. The final visual outcome was very poor in all four eyes, i.e., CFCF or less.

\section{Post-operative complications at 6 months}

The most common complication seen at the 6-month follow-up visit was a failed graft $(\mathrm{n}=7)$. The pre-operative indication seen in these cases were corneal scar $(\mathrm{n}=3)$, post-therapeutic PK $(\mathrm{n}=2)$, adherent leucomas $(\mathrm{n}=1)$, keratoconus $(\mathrm{n}=1)$. The most common cause in the follow-up period leading to graft failure was graft infection, especially fungal $(\mathrm{n}=4)$. Peripheral anterior synechiae and raised IOP were noted in one eye, and in one eye, loose sutures and flat anterior chamber, hemorrhagic choroidal detachment finally led to failed graft. The other complications noted at 6-month follow-up are scar due to infection $(\mathrm{n}=2)$, persistent graft edema $(\mathrm{n}=1)$ due to graft-host disparity, and persistent epithelial defect in early post-operative period for which resuturing done epithelial defect healed but graft became hazy due to edema.

\section{Post-operative astigmatism}

Suture removal was done according to the steep meridian only 6 months after surgery. Total 28 eyes with clear grafts completed 6-month follow-up, among which 6 have completed one-year follow-up. Among the eyes that completed post-operative 6-month follow-up with clear grafts, BCVA with spectacles ranges from $6 / 12$ to $6 / 60$ (Tab. 2). Among the eyes which completed post-operative one-year follow-up, BCVA with spectacles ranges from $6 / 36$ to $6 / 18$. Astigmatism ranges from 2 to 
Table 2. Vision at 6-month and one-year post-operative follow-up

\begin{tabular}{|l|c|c|}
\hline \multirow{2}{*}{ Vision } & \multicolumn{2}{|c|}{ Post-operative follow-up } \\
\cline { 2 - 3 } & Six months & One year \\
\hline $6 / 60-6 / 36$ & 7 & 2 \\
\hline $6 / 24-6 / 12$ & 15 & 4 \\
\hline
\end{tabular}

8 dioptres. With suture removal in the steep axis, it was corrected up to a maximum of 6 dioptres.

Among 6 eyes that underwent 1 -year follow-up all sutures were removed in 2 eyes because of protruding and torn sutures in which astigmatism reverted. In our series, we found graft survival did not
Table 3. Astigmatic correction achieved with suture removal

\begin{tabular}{|l|c|c|}
\hline & $\begin{array}{c}\text { Astigmatism before } \\
\text { suture removal [D] }\end{array}$ & $\begin{array}{c}\text { Astigmatism after } \\
\text { suture removal [D] }\end{array}$ \\
\hline Six-month follow-up \\
\hline 19 & $2-4$ & $0-1$ \\
\hline 9 & $4-8$ & $2-3$ \\
\hline One-year follow-up \\
\hline 4 & $2-4$ & $0-1$ \\
\hline 2 & $2-4$ & $2-3$ \\
\hline
\end{tabular}

differ significantly in small size grafts $(7.5 \times 8 \mathrm{~mm})$ $(\mathrm{n}=57)$, or large size grafts $(8 \times 8.5 \mathrm{~mm})(\mathrm{n}=7)$

\begin{tabular}{|c|c|c|c|c|}
\hline \multirow{2}{*}{ Variables } & \multirow{2}{*}{ Total number } & \multirow{2}{*}{ Number of graft failures } & \multicolumn{2}{|c|}{ Univariable } \\
\hline & & & Risk ratio & p-value \\
\hline \multicolumn{5}{|l|}{ Gender } \\
\hline Male & $48(67.6 \%)$ & 3 & 1 & \multirow[b]{2}{*}{0.1} \\
\hline Female & $23(32.4 \%)$ & 5 & $3.48(0.76-15.83)$ & \\
\hline Age $\leq 60$ years & $52(73.23 \%)$ & 8 & 1 & \\
\hline Age $>60$ years & $19(26.76 \%)$ & 0 & $0.1(0.01-2.9)$ & 0.2 \\
\hline \multicolumn{5}{|l|}{ Graft size $[\mathrm{mm}]$} \\
\hline $8 / 8.5$ & 7 & 1 & 1 & \multirow{7}{*}{0.8} \\
\hline $7.5 / 8$ & 57 & 7 & $1.56(0.09-8.06)$ & \\
\hline $7 / 7.5$ & 2 & & & \\
\hline $7.5 / 8.5$ & 1 & & & \\
\hline $7.5 / 7.0$ & 2 & & & \\
\hline $8.5 / 8.0$ & 1 & & & \\
\hline $8.5 / 9$ & 1 & & & \\
\hline \multicolumn{5}{|l|}{ Type of surgery } \\
\hline PK only & $34(47.88 \%)$ & 2 & 1 & \multirow{3}{*}{0.2} \\
\hline PK + PCIOL & $28(39.43 \%)$ & 4 & $3.13(0.41-14.25)$ & \\
\hline PK + APHAKIA & $6(8.45 \%)$ & 1 & $3.53(0.22-36.38)$ & \\
\hline $\mathrm{PK}+$ anterior vitrectomy & $2(2.81 \%)$ & 1 & $9.2(0.52-138.69)$ & \\
\hline $\mathrm{PK}+\mathrm{SFIOL}$ & $1(1.40 \%)$ & & & \\
\hline \multicolumn{5}{|l|}{ History of graft failure } \\
\hline Yes & 10 & 2 & 1 & \multirow{2}{*}{0.8} \\
\hline No & 61 & 6 & $0.49(0.09-2.79)$ & \\
\hline \multicolumn{5}{|l|}{ Postoperative glaucoma } \\
\hline Yes & 2 & 2 & 1 & \multirow{2}{*}{0.02} \\
\hline No & 69 & 6 & $0.087(0.09-2.79)$ & \\
\hline \multicolumn{5}{|l|}{ Graft infection } \\
\hline Yes & 6 & 4 & & 0.2 \\
\hline No & 55 & & & \\
\hline
\end{tabular}


$(p=0.8)$. Graft survival did not shown difference $(\mathrm{p}=0.2)$ in different surgical types such as $\mathrm{PK}$ $(\mathrm{n}=34), \mathrm{PK}+\mathrm{PCIOL}(\mathrm{n}=28), \mathrm{PK}+$ Aphakia $(n=6)$ and PK with anterior vitrectomy $(n=2)$.

\section{DISCUSSION}

The long-term success rate of corneal transplant surgery reduces to $73 \%$ at $5 \mathrm{yr}, 60 \%$ at $10 \mathrm{yr}$, and $46 \%$ at $15 \mathrm{yr}$ as in the Australian Corneal Graft Registry (ACGR). Studies by Mohammad Zare et al. [4] and Felipe et al. [5] demonstrated that the most common indication for $\mathrm{PK}$ is keratoconus [6]. Various graft registries show the indications for surgery: keratoconus, other corneal dystrophies, followed by aphakic and pseudophakic bullous keratopathies [7-9].

In this study, the graft survival rate at first, second, and fifth year for first-time grafts was $79.6 \%, 68.7 \%$, and $46.5 \%$, respectively [10]. This difference is due to patient profile, indications for surgery, differences in the cornea's storage methods, and socioeconomic factors. In our study, we observed a significant correlation between the prognosis of the case and graft survival. In another study, conducted at L.V. Prasad Eye Institute, India [10], the survival rate for corneal dystrophies was higher (56\%, 5-year survival) and for previously failed grafts was the lowest $(21.2 \%$, 5-year survival).

In our study, the extent of deep vascularization did not correlate with graft survival, but the presence or absence of it did. A study by Price et al. showed eyes with deep stromal vascularization are three times more likely to reject a graft (RR: 2.7, CI: $1.6-4.8, \mathrm{p}<0.01)$ [11].

In our study, graft survival was lower (12 months) in patients with previously failed grafts than in patients with first-time grafts. A survey by Khodadoust shows a rejection rate of $40 \%$ after the first graft, $68 \%$ - after the second, and $80 \%$ - after the third graft [12]. Our study did not find a correlation between surgical factors such as graft size, $\mathrm{PK}$, and $\mathrm{PK}$ with associated procedures with graft survival.

A study by Dandona et al. explains the causes of graft failures, such as rejection (29.2\%), increased IOP (16.9\%), infections (15.4\%), and surface problems (12.7\%) [13].

The most common indication in our study was the corneal scar. This is because most of the patients who underwent PK in this study belong to low so- cioeconomic status. Most patients were agricultural workers who suffered occupational injuries and corneal ulcers, leading to a corneal scar. The second most common cause for PK in this study were adherent leucomas caused by perforated corneal ulcers or a penetrating injury of the globe involving the cornea. These situations are common in agricultural workers and other low socioeconomic working groups. Our study is comparable to another study made in India by Dandona et al. [13] regarding the percentage of indications. In their research, the most common indication for $\mathrm{PK}$ was a corneal scar (28.1\%) which is comparable to our study (28\%).

In our study, the final BCVA of $6 / 36$ or better was achieved in $65 \%$. The results are comparable to a study by Joshi et al. where graft survival at 1 -year follow-up was $65 \%$ [14].

Most of the patients who underwent PK are between 40 and 60 years. These patients are mostly agricultural workers and other poor socioeconomic occupational workers who are prone to ocular injuries and neglect of eye care.

The mean age of the patients was $51.84 \pm 13.74$. In another study by Joshi et al., the mean age of the patients was $55.24 \pm 17.90$.

The male: female ratio in the present study is close to 2:1. Another study conducted in India showed a male:female ratio of 7:3 [14]. These results show gender discrimination in the utilization of health and treatment resources in developing countries like India.

The overall better visual outcome for PK, including all causes, is 66\% (minimum follow-up period is 3 months and the maximum is one year). The results are comparable to those observed by Joshi et al., where the graft quality was good in $64.1 \%$ of cases [14]. In western countries, the success rate is close to or higher than $80 \%$ in most studies. Muraine et al. reported a success rate of $79 \%$ at 1 -year follow-up. At 5-year follow-up overall graft survival rate was $66 \%$ in the survey by Beckingsale et al $[15,16]$.

The success rate for corneal scars is around $75 \%$ - 15 clear grafts among the 20 eyes operated for corneal scars. For adherent leucomas, it is $83 \%$ - 10 clear grafts out of 12 eyes operated. It contrasts with the studies by Bhargav [17], the ACGR report, and the survey made by Joshi et al., where the success rate is higher for non-vascular corneal opacities compared to adherent leucomas and vascular corneal scar. This variation in the present study could be due to sample size variation. 
The success rate for vascular corneas is $71.8 \%$ in a study by Mohan [18]. The outcome of repeat graft depends upon the etiology for which primary graft was carried out. The failure chances are higher for keratoconus (17\%) and doubled in Fuchs' endothelial dystrophy regrafts (33\%).

The outcome of pseudophakic bullous keratopathy treatment was clear grafts in 9 out of 11 eyes operated. Among them, one had glaucomatous optic atrophy and poor vision. In two eyes, the graft failed.

The success rate for pseudophakic bullous keratopathy (PBK) in the study by Vinay Agrawal [19] at six months follow-up was $66.6 \%$. In another study by Schraepen, the vision was improved in bullous keratopathy with PCIOL, but it didn't improve with bullous keratopathy associated with aphakia and ACIOL. Most of the primary grafts were performed due to non-healing or perforating corneal ulcer or an impending perforation. In the eyes in which repeat graft was performed, the main reason for regraft was the primary graft's failure. In this study, the graft was clear in 7 eyes out of 10 eyes with a success rate of $70 \%$. In the study by Srinivasan et al. [20], the success results of regraft were around $82 \%$. Post-operative glaucoma occurred in 2 cases out of 71 eyes operated. We routinely prescribe timolol maleate $0.5 \%$ eye drops BID in the postoperative period unless otherwise the drug is contraindicated. The incidence of glaucoma is $21.5 \%$ in the study made by França et al. [21]. The risk factors for the development of glaucoma are post-traumatic keratoconus. The challenging tasks in the management of post-PK glaucoma are difficulty in measuring IOP by Goldamanns appalanation tonometry, refractory to medical management, and poor outcome for a surgical approach. According to Huber et al. [22], the post-PK glaucoma incidence was $8.7 \%$, and preoperative glaucoma was the significant risk factor $(62 / 160)$.

Graft infection occurred in 6 of 71 cases, out of which only one eye retained satisfactory vision. In all these cases, the clinical findings suggested fungal infection. Out of 6 eyes with graft infection, 4 underwent repeat graft. The primary graft was performed for non-healing or perforating corneal ulcers. These patients had poor compliance with medication and poor eye hygiene and belonged to a low socioeconomic status community. According to a study by Tixier et al. [23], 25\% of infections occur in repeat grafts where the indication for the primary graft was a corneal ulcer.
Out of all 71 eyes operated, 28 eyes underwent PK + PCIOL implantation in the same sitting. Good visual acuity was achieved in 17 out of 28 eyes $(60.7 \%)$. Good visual acuity was achieved in 27 eyes out of 34 eyes operated in cases of PK alone $(79.4 \%)$, and the result was statistically significant $(\mathrm{p}<0.001)$. In the study by Zheng [24], $62 \%$ of eyes achieved a satisfactory visual outcome in PK + PCIOL surgery.

In our study, the reason for poor outcomes in the $\mathrm{PK}+\mathrm{IOL}$ group were: failed grafts in $4(14 \%)$ eyes, graft opacity with IMSC in 1 eye (3.5\%), IMSC in 1 eye $(3.5 \%)$, optic atrophy in 1 eye (3.5\%), macular hole in 1 eye $(3.5 \%)$, clear graft with astigmatism in 3 eyes $(10.7 \%)$ which have been completed only three months postop. Graft failure was noted in 2 eyes $(5.8 \%)$ in PK surgical group, GOA in 1 eye $(2.9 \%)$, clear grafts with astigmatism in 4 eyes (11.7\%).

In a study by Jonas et al. [25] the mean post-operative visual acuity and the mean gain in visual acuity were $0.33 \pm 0.21$ and $0.25 \pm 0.20$, respectively. Compared with the preoperative measurements, mean visual acuity increased in 129 patients (129/135, 95.6\%) who underwent PK + PCIOL. One eye underwent PK + scleral fixated IOL, which achieved a visual acuity of $6 / 18$.

The left aphakic eyes and required vitrectomy were associated with the poor visual outcome comparing to $\mathrm{PK}+\mathrm{PCIOL}$ implantation group. The most common indication for $\mathrm{PK}$ in the developed countries is keratoconus. The graft survival rate was approximately $95 \%$ in $\mathrm{PK}+\mathrm{PCIOL}$ implantation group. Among PK + PCIOL implantation group, one achieved good visual outcome and graft clarity, but, in another case, the graft failed.

Limitations of this study are a small sample size and short follow-up time. Various preoperative conditions will have different outcomes for the same procedure. Hence, comparison between the outcome for different situations is difficult.

\section{CONCLUSION}

Most of the patients who underwent PK are between 40 and 60 years with a higher male prevalence. The most common indication for PK is corneal scar followed by adherent leucomas. Two out of three persons who underwent PK would have a satisfactory visual outcome. PK combined with PCIOL in a single sitting allowed to achieve a good visual outcome in many cases. However, 
the visual outcome compared to $\mathrm{PK}$ alone is better than PK + PCIOL. The trephination of the diseased cornea of $7.5 \mathrm{~mm} / 8 \mathrm{~mm}$ graft of size was associated with good visual outcome. The most common immediate post-operative complication was graft edema, and the most common late complication is graft failure. The final visual outcome was better in non-vascularized scars compared to vascularized corneal scars. Even for the repeat PK, the success rate is around $66 \%$ on par with primary PK. The final visual outcome is poor when corneal pathologies are associated with other pathologies like glaucoma, uveitis, and posterior segment pathologies.

\section{Conflict of interests}

The authors declare that there is no conflict of interest.

\section{Funding}

No specific grant from any funding agency in the public, commercial, or not-for-profit sectors.

\section{Aknowledgments}

Dr. Nasrin acknowledged Dr. Veena for guiding the research work of DNB.

\section{REFERENCES}

1. Thylefors $B$, Négrel $A D$, Pararajasegaram $R$, et al. Global data on blindness. Bull World Health Organ. 1995; 73(1): 115-121, indexed in Pubmed: 7704921.

2. Dandona $L$, Dandona $R$, John RK. Estimation of blindness in India from 2000 through 2020: implications for the blindness control policy. Natl Med J India. 2001; 14(6): 327-334, indexed in Pubmed: 11804362

3. Pascolini D, Mariotti SP. Global estimates of visual impairment: 2010. Br J Ophthalmol. 2012; 96(5): 614-618, doi: 10.1136/bjophthalmol-2011-300539, indexed in Pubmed: 22133988.

4. Zare $M$, Javadi MA, Einollahi $B$, et al. Changing indications and surgical techniques for corneal transplantation between 2004 and 2009 at a tertiary referral center. Middle East Afr J Ophthalmol. 2012; 19(3): 323-329, doi: 10.4103/0974-9233.97941, indexed in Pubmed: 22837628

5. Felipe AF, Hammersmith KM, Nottage JM, et al. Indications, visual outcome, and ectasia in clear corneal transplants 20 years old or more. Cornea. 2013; 32(5): 602-607, doi: 10.1097/IC0.0b013e31825ec42f, indexed in Pubmed: 22968363.

6. Williams KA, Lowe M, Bartlett C, et al. All Contributors. Risk factors for human corneal graft failure within the Australian corneal graft registry. Transplantation. 2008; 86(12): 1720-1724, doi: 10.1097/ TP.0b013e3181903b0a, indexed in Pubmed: 19104411

7. Cosar CB, Sridhar MS, Cohen EJ, et al. Indications for penetrating keratoplasty and associated procedures, 1996-2000. Cornea. 2002; 21(2): 148-151, doi: 10.1097/00003226-200203000-00003, indexed in Pubmed: 11862083.

8. Siganos CS, Tsiklis NS, Miltsakakis DG, et al. Changing indications for penetrating keratoplasty in Greece, 1982-2006: a multicenter study.
Cornea. 2010; 29(4): 372-374, doi: 10.1097/ICO.0b013e3181bd44a1, indexed in Pubmed: 20164748.

9. Coster DJ, Williams KA. The impact of corneal allograft rejection on the long-term outcome of corneal transplantation. Am J Ophthalmol. 2005; 140(6): 1112-1122, doi: 10.1016/j.ajo.2005.07.024, indexed in Pubmed: 16376660.

10. Dandona L, Naduvilath TJ, Janarthanan $M$, et al. Survival analysis and visual outcome in a large series of corneal transplants in India. Br J Ophthalmol. 1997; 81(9): 726-731, doi: 10.1136/bjo.81.9.726, indexed in Pubmed: 9422922.

11. Price M0, Thompson RW, Price FW. Risk factors for various causes of failure in initial corneal grafts. Arch Ophthalmol. 2003; 121(8): 1087-1092, doi: 10.1001/archopht.121.8.1087, indexed in Pubmed: 12912684.

12. Khadadoust AA. The allograft rejection reaction: The leading cause of late failure of clinical corneal grafts. In: Jones BR. ed. Corneal Graft Failure. Elsevier, New York 1973.

13. Dandona L, Naduvilath TJ, Janarthanan M, et al. Survival analysis and visual outcome in a large series of corneal transplants in India. Br J Ophthalmol. 1997; 81(9): 726-731, doi: 10.1136/bjo.81.9.726, indexed in Pubmed: 9422922.

14. Joshi SA, Jagdale SS, More PD, et al. Outcome of optical penetrating keratoplasties at a tertiary care eye institute in Western India. Indian J Ophthalmol. 2012; 60(1): 15-21, doi: 10.4103/0301-4738.91337, indexed in Pubmed: 22218240.

15. Muraine M, Sanchez C, Watt L, et al. Long-term results of penetrating keratoplasty. A 10-year-plus retrospective study. Graefes Arch Clin Exp Ophthalmol. 2003; 241(7): 571-576, doi: 10.1007/s00417-003-0691-z, indexed in Pubmed: 12819978.

16. Beckingsale $\mathrm{P}$, Mavrikakis I, Al-Yousuf $\mathrm{N}$, et al. Penetrating keratoplasty: outcomes from a corneal unit compared to national data. $\mathrm{Br}$ J Ophthalmol. 2006; 90(6): 728-731, doi: 10.1136/bj0.2005.086272, indexed in Pubmed: 16714264.

17. Bhargava N. Healing of a graft in vascularized and non-vascularized corneal lesions. Indian J Ophthalmol. 1990; 38(4): 156-158, indexed in Pubmed: 2086463.

18. Mohan M, Panda A, Kumar TS. Results of penetrating keratoplasty in vascularized corneas. Ann Ophthalmol. 1990; 22(6): 235-238, indexed in Pubmed: 1695074.

19. Agrawal V, Vagh MM, Sangwan V, et al. Penetrating keratoplasty for pseudophakic bullous keratopathy. Indian J Ophthalmol. 1994; 42(2): 75-80, indexed in Pubmed: 7927635.

20. Srinivasan M, Rao GN, Aquavella JV. Corneal regrafting. Analysis of results. Indian J Ophthalmol. 1984; 32(5): 402-404, indexed in Pubmed: 6400104.

21. França ET, Arcieri ES, Arcieri RS, et al. A study of glaucoma after penetrating keratoplasty. Cornea. 2002; 21(3): 284288, doi: $10.1097 / 00003226-200204000-00009$, indexed in Pubmed: 11917177.

22. Huber KK, Maier AKB, Klamann MKJ, et al. Glaucoma in penetrating keratoplasty: risk factors, management and outcome. Graefes Arch Clin Exp Ophthalmol. 2013; 251(1): 105-116, doi: 10.1007/s00417012-2065-x, indexed in Pubmed: 22644096.

23. Tixier J, Bourcier T, Borderie V, et al. [Infectious keratitis after penetrating keratoplasty]. J Fr Ophtalmol. 2001; 24(6): 597-602, indexed in Pubmed: 11460055.

24. Zheng YR, Sheng MJ. [Clinical observations on the combined operation of penetrating keratoplasty, extracapsular cataract extraction and IOL implantation]. Zhonghua Yan Ke Za Zhi. 1990; 26(3): 135-137, indexed in Pubmed: 2397662.

25. Jonas JB, Rank RM, Budde WM, et al. Factors influencing visual outcome after penetrating keratoplasty combined with intraocular lens implantation. Eur J Ophthalmol. 2003; 13(2): 134-138, doi: 10.1177/ 112067210301300203, indexed in Pubmed: 12696631. 